\title{
Presence of Mycoplasma fermentans in the bloodstream of Mexican patients with rheumatoid arthritis and IgM and IgG antibodies against whole microorganism Constantino Gil113, Antonio Rivera1,2,3, David Bañuelos², Salvador Salinas², Ethel García-Latorre ${ }^{3}$ and Lilia Cedillo*1
}

Address: ${ }^{1}$ Centro de Investigaciones en Ciencias Microbiológicas, Instituto de Ciencias, Benemérita Universidad Autónoma de Puebla, Edificio 103J, Ciudad Universitaria, Puebla, Pue, México, 2 Servicio de Reumatología, Centro Médico Manuel Ávila Camacho, Instituto Mexicano del Seguro Social, 2 Norte y 18 Oriente, Puebla, Pue, México and ${ }^{3}$ Escuela Nacional de Ciencias Biológicas, Instituto Politécnico Nacional, Prolongación de Plan de Ayala y Carpio, México

Email: Constantino Gil - cgil@siu.buap.mx; Antonio Rivera - jart70@yahoo.com; David Bañuelos - davra@hotmail.com; Salvador Salinas - salinas_reuma@ hotmail.com; Ethel García-Latorre - ethelagarcia@hotmail.com; Lilia Cedillo* - lcedil@siu.buap.mx

* Corresponding author

Published: 3 August 2009

BMC Musculoskeletal Disorders 2009, 10:97 doi:10.1 186/147|-2474-10-97

This article is available from: http://www.biomedcentral.com//47/-2474//0/97

(C) 2009 Gil et al; licensee BioMed Central Ltd.

This is an Open Access article distributed under the terms of the Creative Commons Attribution License (http://creativecommons.org/licenses/by/2.0), which permits unrestricted use, distribution, and reproduction in any medium, provided the original work is properly cited.
Received: 19 December 2008

Accepted: 3 August 2009

\begin{abstract}
Background: Increasing evidence incriminates bacteria, especially Mycoplasma fermentans, as possible arthritogenic agents in humans. The purpose of this study was to investigate $M$. fermentans in the bloodstream of patients with rheumatoid arthritis.

Methods: Two hundred and nineteen blood samples from patients with rheumatoid arthritis, systemic lupus erythematosus, antiphospholipid syndrome, and healthy individuals were screened by bacterial culture and direct PCR in order to detect mycoplasmas; IgM and IgG against $M$. fermentans PGI8 were also detected by ELISA and Immunoblotting assays in patients with rheumatoid arthritis and healthy individuals.
\end{abstract}

Results: Blood samples from patients with antiphospholipid syndrome and healthy individuals were negative for mycoplasma by culture or direct PCR. In blood samples from patients with systemic lupus erythematosus were detected by direct PCR $M$. fermentans in $2 / 50(2 \%)$, M. hominis in $2 / 50(2 \%)$ and $U$. urealyticum in I/50 (0.5\%). In patients with RA M. fermentans was detected by culture in 13/87 blood samples and in 13/87 by direct PCR, however, there was only concordance between culture and direct PCR in six samples, so M. fermentans was detected in $20 / 87(23 \%)$ of the blood samples from patients with RA by either culture or PCR. Antibody-specific ELISA assay to M. fermentans PG I 8 was done, IgM was detected in sera from 40/87 patients with RA and in sera of $7 / 67$ control individuals, IgG was detected in sera from 48/87 RA patients and in sera from 7/67 healthy individuals. Antibody-specific immunoblotting to $M$. fermentans PGI 8 showed IgM in sera from $35 / 87$ patients with RA and in sera from 4/67 healthy individuals, IgG was detected in sera from $34 / 87$ patients and in sera from $5 / 67$ healthy individuals.

Conclusion: Our findings show that only M. fermentans produce bacteremia in a high percentage of patients with RA. This finding is similar to those reported in the literature. IgM and IgG against M. fermentans PGI 8 were more frequent in patients with RA than healthy individuals. 


\section{Background}

Rheumatoid arthritis (RA) is a chronic inflammatory disease, which results from a complex interplay of factors both at the systemic level and at the site of inflammation [1].

Rheumatoid arthritis affects about $1.5 \%$ of the world population and occurs more frequently in women than in men $(2.5: 1)[2,3]$. Although the immune response plays an important role in RA, the aetiology is unknown. There are hypotheses which suggest that bacterial agents play an important role in the onset of the disease, but their causative link with RA remains controversial, because the studies have not established a strong enough association [4-6].

Mycoplasmas are a major cause of acute and chronic arthritis in animals and can induce arthritis in animal experimental models [7-9]. Mycoplasmas have been considered possible arthritogenic agents for humans since the 1960 's when mycoplasmas were isolated from arthritic joints of animals, especially Mycoplasma fermentans, which was isolated from synovial fluids (SF) [10]. There is increasing evidence to suggest that mycoplasmas may play a role in RA [11-13]. The other mycoplasmas that are less frequently involved in human RA are: $M$. pneumoniae, $M$. hominis, M. genitalium, M. salivarium, M. orale, and Ureaplasma urealyticum [13]. The purpose of this study was to investigate $M$. fermentans in the bloodstream of patients with RA.

\section{Methods \\ Subjects}

One hundred and fifty two patients who attended the Rheumatology Service of the Hospital Manuel Avila Camacho del Instituto Mexicano del Seguro Social in Puebla, México were included in the study. A rheumatologist examined the patients and all fulfilled the American College of Rheumatology criteria. The patients' ages ranged between 25 and 79 yr. All patients with RA were in the acute phase of the disease and had not been under antibiotic treatments for at least six weeks before the sample was taken.

Sixty-seven individuals without RA, systemic lupus erythematosus (SLE), antiphospholipid syndrome (APS) or infectious disease were included in the study as healthy individuals, since in several cases of these diseases an inflammatory response in the joint is observed. Ages in the healthy individuals ranged between 20 and $60 \mathrm{yr}$. All healthy individuals were not under antibiotic or other drugs treatment. The ethics committee of the Hospital Manuel Avila Camacho del Instituto Mexicano del Seguro Social approved this study and informed patient consent was obtained.

\section{Specimens}

Peripheral whole blood samples from patients and healthy individuals were collected in order to detect mycoplasmas by culture and direct PCR. Antibodies specific to M. fermentans were also investigated. Blood samples, which were collected in citrate-containing or non anticoagulant tubes, were stored at $-20^{\circ} \mathrm{C}$ until use.

\section{Mycoplasmal culture}

One hundred microliters of plasma of patients and healthy individuals were dip-inoculated in $900 \mu \mathrm{L}$ of three different media: SP4 medium with glucose, SP4 medium with urea and SP4 medium with arginine, in order to isolate fermentative mycoplasmas, $U$. Urealyticum and $M$. hominis respectively. An SP4 tube with each media was incubated as control. Three serial ten-fold dilutions were incubated at $37^{\circ} \mathrm{C}$ until the indicator phenol red changed to yellow for fermentative mycoplasmas or red to non-fermentative, which indicate mycoplasma growth, on the other hand, cultures were considered negative when the indicator did not change after 30 days for M. pneumoniae and $M$. fermentans, 4 days for $M$. hominis and $U$. urealyticum. Control cultures were prepared as follows: one hundred microliters of $M$. fermentans PG18, M. pneumoniae Eaton strain, M. hominis, M. penetrans GTU and U. urealyticum were dip-inoculated into $900 \mu \mathrm{L}$ of plasma, and three serial ten-fold dilutions were done into SP4 media with glucose, urea or arginine and incubated at $37^{\circ} \mathrm{C}$ for 48 hours or until the indicator changed showing mycoplasma growth. Likewise, one hundred microliters of each reference strains were dip-inoculated into $900 \mu \mathrm{L}$ of the SP4 media with the respective substrate. Dilutions are recommended when tissues or corporal fluids are cultivated, because some inhibitory substances for mycoplasmas may be present. Positive mycoplasma cultures were confirmed using the PCR technique. All the blood samples were directly cultured on blood agar plates to detect any aerobes or aerobic facultative bacteria.

\section{DNA extraction from blood samples}

Red blood cells $(2.5 \mathrm{ml})$ were lysed with nanopure water $(10 \mathrm{ml})$ at room temperature for $10 \mathrm{~min}$ and centrifuged at $3,000 \times g$ for $10 \mathrm{~min}$. The pellet containing white cells was treated as follow: Triton X-100 $(1 \%, 10 \mathrm{ml})$ was added and mixed gently for $5 \mathrm{~min}$. After centrifugation at $3,000 \times g$ for $10 \mathrm{~min}$, SDS $(1 \%, 10 \mathrm{ml})$ was added and mixed gently for $10 \mathrm{~min}, \mathrm{NaCl}(0.1 \mathrm{M}, 10 \mathrm{ml})$ was added for $10 \mathrm{~min}$ followed by the addition of $10 \mathrm{ml}$ of cold ethanol. After centrifugation at $10,000 \times g$ for $10 \mathrm{~min}$, the supernatant was discarded and the DNA was recovered in $500 \mu \mathrm{L}$ of nanopure water and stored at $-20^{\circ} \mathrm{C}$. DNA was also extracted from a $1.4 \mathrm{ml}$ whole blood sample seeded with $100 \mu \mathrm{L}$ of $M$. fermentans PG18 for use as a positive control sample. 


\section{DNA extraction from mycoplasmal cultures}

DNA was extracted from Mycoplasma-positive cultures as follows: $1.5 \mathrm{ml}$ of culture was centrifuged at $12,000 \times \mathrm{g}$ for $20 \mathrm{~min}$, the supernatant was discarded and the pellet was suspended in $100 \mu \mathrm{L}$ of a solution containing $10 \mathrm{mM}$ Tris$\mathrm{HCl} \mathrm{pH}$ 8.3, $100 \mathrm{mM} \mathrm{KCl}, 2.5 \mathrm{mM} \mathrm{MgCl}_{2}, 1 \%$ Tween-20, $1 \%$ Triton X-100 and $0.5 \mathrm{mg} / \mathrm{ml}$ of proteinase K. Samples were heated at $60^{\circ} \mathrm{C}$ for $60 \mathrm{~min}$ and immediately brought to $90^{\circ} \mathrm{C}$ for $10 \mathrm{~min}$, then placed in an ice bath for $20 \mathrm{~min}$ and stored at $-20^{\circ} \mathrm{C}[14]$.

\section{PCR assays}

PCR detection of Mycoplasma sp. DNA using 16 s RNA gene primers AR1 and AR2 was performed according to Shidu et al. [14]. The primers used to identify species are shown in Additional file 1[15-19]. Amplification was performed in a total volume of $50 \mu \mathrm{L}$ containing $50 \mathrm{mM} \mathrm{KCl}$, $1.5 \mathrm{mM} \mathrm{MgCl}_{2}, 10 \mathrm{mM}$ Tri-HCl (pH 8.3), $0.2 \mathrm{mM}$ of each dNTP (Amersham Pharmacia Biotech, USA) and 1 unit of ampliTaq polymerase (Gibco, BRL, USA). The sample to be analysed was always added last. A diluted lysate of $M$. fermentans PG18 or $M$. pneumoniae (Eaton strain) or $M$. penetrans GTU-54 or M. hominis or U. urealyticum corresponding to 100 colour-changing units and sterile water were used as positive and negative controls, respectively. Amplification consisted of a 10-min thermal delay step at $95^{\circ} \mathrm{C}$, followed by 40 cycles comprising a $20 \mathrm{~s}$ denaturation step at $95^{\circ} \mathrm{C}$, a $1-$ min annealing step at $62^{\circ} \mathrm{C}$, a 1 -min elongation step at $72^{\circ} \mathrm{C}$, and a final 4-min elongation step at $72^{\circ} \mathrm{C}$ PCRS were performed with an automated thermocycler (MJ Research, Watertown, MA.). PCR products were analysed by $2 \%$ agarose gels electrophoresis and ethidium bromide staining [14].

\section{Antibody-specific ELISA assay}

The antibodies IgM and IgG to M. fermentans PG18 in sera were measured by ELISA using M. fermentans PG18 whole cells adjusted to an OD $600=1$ and performed as described by Horowitz et al., 1995 [20]. Samples with absorbance equal to or higher than the mean of the control group plus three standard deviations for IgM and IgG were considered positive.

\section{Antibody-specific immunoblotting assay}

The antigen used was M. fermentans PG18 whole cells adjusted to an OD $600=1$ and $750 \mu \mathrm{L}$ of this solution was mixed with $250 \mu \mathrm{L}$ of sample buffer $4 \times(40 \%$ glycerol, 240 mM Tris/HCl pH 6.8, 0.04\% bromophenol blue, 5\% betamercaptoethanol) and boiled during ten minutes. Immunoblotting according to Horowitz et al. 1998 [21] was applied to detect IgM and IgG specific to $M$. fermentans PG18. The antibodies were detected by incubating 2 nitrocellulose (NC) strips in each patient's serum diluted 1:100 in PBS at $37^{\circ} \mathrm{C}$ for $2 \mathrm{~h}$. Peroxidase-conjugates anti-human IgM or IgG were diluted 1:5000 in PBS and one strip was used in order to detect every one of the antibody isotypes. A rabbit was immunized with $M$. fermentans PG18 and the serum was used as positive control (line 11, figure 1). Peroxidase substrate was prepared according to manufacturer (Sigma Co.) and the bound peroxidase activity was visualized using the incubation of the NC strips for 5 to $20 \mathrm{~min}$ at room temperature. The enzymatic reaction was stopped and stabilized by washing the NC strips in a solution containing $13 \mathrm{ml}$ of dioctyl sodium sulfosuccinate-ethanol in $37 \mathrm{ml}$ of water.

\section{Statistical analysis}

Chi squared test was done in order to compare the presence of antibodies against M. fermentans in patients and healthy individuals.

\section{Results \\ Patients}

Eighty seven patients with RA, 50 patients with SLE and 15 patients with APS were included in the study; all of them had varying times of disease, duration ranging from 2-25 years. All patients with autoimmune diseases were receiving weekly immunosuppressive therapy (50\% receiving prednisone at 5-10 mg and/or methotrexate at 5-10 mg). All patients were receiving therapy with non-steroidal, anti-inflammatory drugs. Thirty percent of the patients had a history of recurrent respiratory or genitourinary tract infections, but at the time of specimen collection there were no signs of infectious disease.

\section{Mycoplasmal culture}

All of the blood samples from patients with SLE, APS and healthy individuals were negative for mycoplasma by culture. Among the 87 peripheral blood samples from patients with RA, thirteen were considered culture-positive for $M$. fermentans because they changed the colour indicator of the media and the pure culture was then identified by PCR (Additional file 2).

\section{Detection of Mycoplasma DNA by Direct PCR}

AR1 and AR2 genus-specific primers, which amplify a 16 s RNA gene fragment, were used to detect mycoplasmas in peripheral blood samples. Mycoplasma spp sequence was amplified in 13/87 samples from patients with RA and 5/ 50 samples from patients with SLE. All the peripheral blood samples from APS patients and healthy individuals were negative. Species-specific PCR primers were then used to determine which mycoplasmas were present. All samples from RA patients in which Mycoplasma spp DNA was amplified were positive for $M$. fermentans DNA, in blood samples from patients with SLE were detected by direct PCR to M. fermentans in 2/50 (2\%), M. hominis in 2/ $50(2 \%)$ and $U$. urealyticum in $1 / 50(0.5 \%)$. Respect to the identification of $M$. fermentans in patients with RA, there was only concordance between culture and direct PCR in 


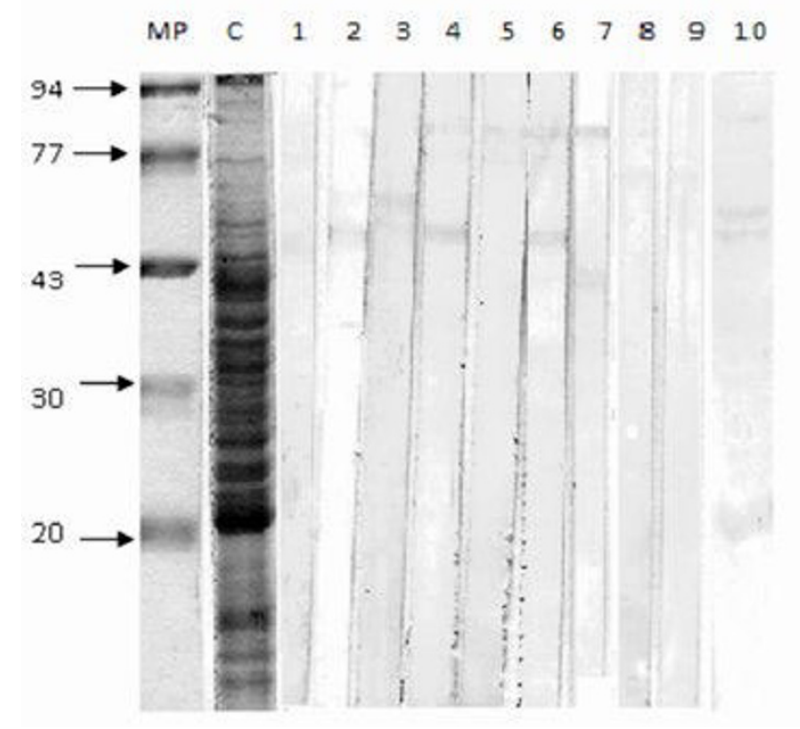

Figure I

Antibodies-specific to P70 and P48 were detected. Line MW molecular weights; line I M. fermentans PG I 8 antigens extracted by heat; line 2, 4, 6, 8 IgM detection; line 3, 5, $7 \mathrm{lgG}$ detection; line 9, 10 negative serum from healthy individuals; line II positive serum from an immunized rabbit with M. fermentans PG I8.

6 patients, so we identified M. fermentans in 20/87 (23\%) patients with RA (Additional file 2).

\section{Antibody-specific ELISA assay}

IgM and IgG against M. fermentans PG18 were measured by ELISA. A threshold level above which samples were deemed positive was determined using a cut-off value generated from results from the control population. IgM against $M$. fermentans PG18 was detected in sera from 40/ 87 patients with RA and in sera of 7/67 healthy individuals. $\mathrm{X}^{2}$ was calculated and association between the presence of IgM antibodies against M. fermentans PG18 and RA patients $(\mathrm{p}<.01)$. IgG was detected in sera from $48 / 87$ RA patients and in sera from $7 / 67$ healthy individuals. There was association between the absence of antibodies against M. fermentans PG18 and healthy individuals ( $\mathrm{p}<$ 0.1 ) using $X^{2}$. A higher percentage of patients than healthy individuals had antibodies against M. fermentans PG18 (Additional file 3).

\section{Antibody-specific immunoblotting assay}

IgM-specific to M. fermentans PG18 was detected in sera from 35/87 patients with RA and in sera from 4/67 healthy individuals. IgG was detected in sera from 34/87 patients and in sera from 5/67 healthy individuals. Figure 1 shows representative results of immunobloting assay, IgM and IgG were detected to P70 and p48. There was a significant difference. $\mathrm{X}^{2}$ was calculated $(\mathrm{p}<0.1)$ (Additional file 3 ).

\section{Discussion}

Infectious agents such as viruses, bacteria, and bacterial components have been hypothesized to play some role in the pathology of RA and other autoimmune diseases based on clinical and pathological findings in humans and animals [22-24]. However, this hypothesis remains unproven. Hernández et al. (1998) studied the recurrence and severity of infections in Mexican patients with RA and found that $48.7 \%$ of the patients suffered from infections related to treatment with steroids and methotrexate [25]. In this study we examined blood samples from RA, SLE, and APS patients for aerobic, aerobic facultative bacteria and mycoplasmas in particular, through culture, PCR, and immunological assays. Although all samples were negative for aerobic or aerobic facultative bacteria, $30 \%$ of the patients had a history of recurrent upper respiratory and genitourinary tract infections, 50\% were being treated with prednisone and/or MTX, and 100\% were being treated with nonsteroidal antinflammatory drugs. These findings are consistent with a role for infectious agents in RA. Mycoplasmas are putative agents in RA because they can produce arthritis in animals [26] and have also been detected in patients with RA [27] and other inflammatory arthritides [28]. However, results have been poorly reproduced, in part because of the difficulties of working with mycoplasmas. Since mycoplasmas are fastidious bacteria that are difficult to culture and identify and also may suffer phenotypic changes in culture, culture techniques and serological assays are not reliable diagnostic tests for mycoplasmal infection. Serology provides evidence of host contact with mycoplasmas, but does not provide evidence of the bacteria in the host. PCR techniques allow sensitive and specific detection of mycoplasmal DNA in various biological samples [29,30], but gives no information about the viable bacteria. To detect whether there is a causal relationship of microorganisms with arthritis it is important the viable bacteria as well as the immune response to the bacteria. That is why we used several techniques to diagnose mycoplasmal infection. In order to obtain reproducible results, we used standard techniques reported for isolation and PCR identification of mycoplasmas and all the risk factors of contamination were avoided.

The AR1 and AR2 primers have been reported as specific to the Mycoplasma genus (they do not cross-react with other bacteria) and can amplify $16 \mathrm{~s}$ RNA gene nucleotide sequences of 30 different species [14]. Using these primers and species-specific primers, we detected $M$. fermentans in $23 \%$ of patients with RA and in $2 \%$ of patients with SLE, but did not detect it in patients with APS or in healthy individuals.

M. fermentans has been previously detected in patients with RA and inflammatory diseases. Schaeverbeke et al. (1997) detected M. fermentans in two patients with RA 
and in one patient with a different inflammatory arthritis. They also reported the isolation of M. hominis, M. salivarium, M. orale, and U. urealyticum from SF and did not find concordance between culture and PCR [13]. Horowitz et al. (2000) detected M. fermentans DNA in SF from $17.6 \%$ of patients with RA and in one patient with undefined arthritis, but it was not detected by culture in any of these patients and they did not detect M. fermentans in other inflammatory or non-inflammatory arthropathies [31]. Gilroy et al. (2001) detected M. fermentans DNA in the SF of $17 \%$ of patients with RA and in $21 \%$ of patients with seronegative arthritis, and they did not detect it in patients with other arthropathies [11]. In contrast, Johnson et al. (2000) and Hoffman et al. (1997) reported higher percentages of detection of DNA of $M$. fermentans by PCR. The former reported M. fermentans in 31/34 patients with RA, and in 9/11 patients with non-rheumatoid inflammatory arthritis, and it was not isolated in patients with osteoarthritis. The latter did not detect M. fermentans in SF or tissues and did not use culture procedures [12,32]. Haier et al. (1999) identified M. fermentans, M. pneumoniae, M. hominis and $M$. penetrans by PCR in leucocytes from patients with RA [27]. In contrast, in this study we did not detect M. pneumoniae or M. penetrans. M. hominis and $U$. urealyticum were only identified by PCR in patients with SLE. Johnson et al. (2007) found by a very sensitive PCR a conserved mycoplasmal 16 S RNA of M. pneumoniae in the SF from patients with RA, osteoarthritis and nonrheumatoid inflammatory arthritis and it was not found in the SF from people with knee injuries or undergoing surgery for knee replacement [33].

Immune and inflammatory responses can be triggered or exacerbated by many factors including infectious agents. Aerobic and anaerobic bacteria, as well as viruses and mycoplasmas, have been considered as important agents in RA. Mycoplasmas have the ability to induce a broad range of inflammatory and immunological events. They are able to induce cytokine production and also activate macrophages, $\mathrm{B}$ and $\mathrm{T}$ lymphocytes. In this study we investigated whether antibodies against $M$. fermentans PG18 were present in sera from patients with RA and healthy individuals. Our results are similar to those reported by Horowitz et al. (2000), who detected antibodies against $M$. fermentans in $50 \%$ of patients with RA and $20 \%$ of patients with other arthritis; however there are differences respect to $M$. fermentans peptides detected, while Horowitz et al. detected antibodies to p107, p48 and p29, we reported antibodies to p70 and p48, the differences probably are due to the different strains and the technique used for the antigen extraction [31]. In contrast Hoffman et al. (1997) found antibodies against M. hominis in 55\% of patients with RA and $88 \%$ juvenile RA patients and they also detect antibodies against this microorganism in patients with other inflammatory disease and controls
[32]. Ramírez et al. (2005) performed a case-control study in which they show a statistical difference when they compare the presence of antibodies against M. pneumoniae in patients with RA and controls [34]. In our study, 20 out of 87 RA patients showed evidence of infection with M. fermentans. Thirteen patients had persistent infection with M. fermentans as evidenced by cultivable bacteria in the blood. All but two of these thirteen displayed an antibody response to $M$. fermentans. These results suggest that viable M. fermentans in blood of patients with RA is common, even though the role of bacteria is not known. In the other hand, it will be important to do studies in order to detect antibodies against $M$. fermentans glycolipid-antigen in patients with RA and other inflammatory arthritides, since Kawahito et al. (2008) detected to GGPL-III in $38.1 \%$ of RA patient's tissues [35].

There is a hypothesis that bacteria may trigger arthritis, and two models are often considered. One model postulates that arthritis is promoted by inflammation due to a chronic infection characterized by the long term presence of low levels of bacteria. The other postulates a "hit and run" phenomenon in which bacteria infect a joint for only a short period of time before being cleared [36], but initiate a cascade of inflammatory events while there, both nonspecific and specific responses that lead to inflammation and arthritis [37]. M. fermentans, which is frequently isolated from joints, may fit into the "hit and run" class. The main contribution of this study is that $M$. fermentans bacteremia was present in a significant number of patients with RA, supporting the idea that M. fermentans is a possible agent to consider in the pathology of RA. These results, and those of previous studies that also detected M. fermentans in RA patients, suggest that patients with RA have been exposed to $M$. fermentans, and that a high percentage of patients develop a systemic mycoplasmal infection $[13,27,31]$, and the contradictory results on his isolation or identification are in part, because this mycoplasma may not be permanently in SF or tissues due to passive carriage or ubiquitous[31], since it has been found in pharynx, saliva peripheral mononuclear cells[38], another fact that support that $M$. fermentans can be associated with RA, was the study of Rivera et al. in an animal model, in which they showed that when this microorganism is inoculated in the trachea it can reach the joint [9]. The role of $M$. fermentans in initiating or perpetuating synovitis should be explored further, but three hypotheses can be considered with respect to the role of mycoplasmas in RA. The first proposes that M. fermentans is a cofactor of the disease in a genetically susceptible host and its role is in the induction of the autoimmune response. On the other hand, the second suggests that RA is produced by the reach of $M$. fermentans in the joint and the liberation of toxic substances or cytokines that produce joint damage [39]. With the same evidence, the third proposes that 
patients with RA are frequently under steroid treatment and steroids may favour systemic infections with M. fermentans.

Since RA has been associated with the presence of autoantibodies including rheumatoid factor, and the role of microorganisms is still unknown, the other important role in this disease is the genetic risk. Histocompatibility antigens (HLA-DR 1/4) in patients with RA have been studied, motif sequences like QKRAA, QRRAA. RRRAA or ESRRAL have been implicated in the susceptibility to develop RA. There are studies that determined the presence of share epitope in microorganisms[40]. Ebringer $e t$ al. (1992) show cross-reactivity between HLA-DR4 and Proteus mirabilis haemolysin [41] although in mycoplasmas there are not studies about the presence of shared epitope, it will be important to study this possibility.

\section{Conclusion}

Our results are similar to those reported in the literature regarding the implication of $M$. fermentans in RA. The main contribution of our study is that only M. fermentans produce bacteremia in a higher percentage of patients with RA. IgM and IgG were detected against p70 and p48 $M$. ferementans antigens. These findings suggests that $M$. fermentans is common in these patients and it may enter through the respiratory tract and blood could be the medium to reach joints, where they may induce an inflammatory or immune response.

\section{Competing interests}

The authors declare that they have no competing interests.

\section{Authors' contributions}

CGJ carried out the samples collection, mycoplasmas' cultures and wrote the paper. JART carried out the PCR assays in order to identify mycoplasmas. DBR and SSS participated in the selection of the patients. EGL participated in the design and coordination. LC conceived the study, performed the statistical analysis and drafted the manuscript.

\section{Additional material}

\section{Additional file 1}

Table 1. Primers used in order to identify Mycoplasma species.

Click here for file

[http://www.biomedcentral.com/content/supplementary/1471-

2474-10-97-S1.doc]

\section{Additional file 2}

Table 2. Detection of M. fermentans by culture, direct PCR and IgM and IgG in patients with RA.

Click here for file

[http://www.biomedcentral.com/content/supplementary/1471-

2474-10-97-S2.doc]

\section{Additional file 3}

Table 3. Antibodies-specific ELISA and immunoblotting assays to M. fermentans in patients with RA and controls.

Click here for file

[http://www.biomedcentral.com/content/supplementary/14712474-10-97-S3.doc]

\section{Acknowledgements}

We thank Dr. J. A. Girón for critical comments. We also thank M. E. Balcazar and E. Herrera for skillful technical help and Elliot Heilman for his careful review of the manuscript.

\section{References}

I. Thomas R, Davis LS, Lipsky PE: Rheumatoid synovium is enriched in mature antigen-presenting dendritic cells. J Immunol 1994, 152:2613-2623.

2. Lawrence RC, Helmick CG, Arnett FC, et al: Estimates of the prevalence of arthritis and selected musculoskeletal disorders in the United States. Arthritis Rheum 1998, 41:778-799.

3. Symmons DP, Barrett EM, Bankhead CR, et al.: The incidence of rheumatoid arthritis in the United Kingdom: results from the Norfolk arthritis register. BrJ Rheumatol 1994, 33:755-759.

4. Behar SM, Porcelli SA: Mechanisms of autoimmune diseases induction: the role of the immune response to microbial pathogens. Arthritis Rheum 1995, 38:458-476.

5. Kempsell EK, Cox JC, McColm AA, Bagshaw AJ, Reece R, Veale JD, et al.: Detection of Mycobacterium tuberculosis group organisms in human and mouse joint tissue by reverse transcriptase PCR: Prevalence in diseased synovial tissue suggests lack of specific association with rheumatoid arthritis. Infect Immun 200I, 69:182I-I83I.

6. Krause A, Kamradt T, Burmester GR: Potential infectious agents in the induction of arthritides. Curr Opin Rheumatol 1996, 8:203-209.

7. Cedillo L, Gil C, Mayagoitia G, Giono S, Cuellar Y, Yáñez A: Experimental arthritis induced by Mycoplasma pneumoniae in rabbits. J Rheumatol 1992, 19:344-347.

8. Kirchhoff H, Binder A, Runge M, Meier B, Jacobs R, Busche K: Pathogenic mechanisms in the Mycoplasma arthritidis polyarthritis in rats. Rheumatol Int 1989, 9:193-196.

9. Rivera A, Yánez A, León G, Gil C, Giono S, Barba E, Cedillo L: Experimental arthritis induced by a clinical Mycoplasma fermentans isolate. BMC Musculoskeletal Dis 2002, 3:15.

10. Williams MH: Recovery of mycoplasmas from rheumatoid sinovial fluid. In Rheumatic Diseases Edited by: Duthie JJR, Alexander WRM. Baltimore: Williams \& Wilkins; 1968: 172-18I.

II. Gilroy CB, Keat A, Taylor-Robinson D: The prevalence of Mycoplasma fermentans in patients with inflammatory arthritides. Rheumatol 200I, 40:1355-1358.

12. Johnson S, Sidebottom D, Bruckner F, Collins D: Identification of Mycoplasma fermentans in synovial fluid samples from arthritis patients with inflammatory disease. J Clin Microbiol 2000, 38:90-93.

13. Schaeverbeke T, Renaudin H, Clerc M, Lequen L, Vernhes JP, De Barbeyrac B, Bannwarth B, Bébéar Ch, Dehais J: Systematic detection of mycoplasmas by culture and polymerase chain reaction (PCR) procedures in 209 synovial fluid samples. Bri J Rheumatol 1997, 36:310-314.

14. Sidhu KM, Rashidbaigi A, Testa D, Liao MJ: Competitor internal standards for quantitative detection of mycoplasmal DNA. FEMS Microbiol Lett 1995, I 28:207-2 I2.

15. Wang RY, Hu H, Dawson WS, Shih MS, Lo SC: Selective detection of Mycoplasma fermentans by polymerase chain reaction and by using a nucleotide sequence within the insertion sequence-like element. J Clin Microbiol 1992, 30:245-248.

16. Inamine JM, Denny TP, Loechel S, Schaper U, Huang CH, Bott KF, Hu PC: Nucleotide sequence of the $P I$ attachment-protein gene of Mycoplasma pneumoniae. Gene 1988, 64:217-219. 
17. Grau O, Kovaci R, Griffais R, Launay V, Montagnier L: Development of PCR-based assays for the detection of two human mollicute species, Mycoplasma penetrans and Mycoplasma hominis. Mol Cell Probes 1994, 8: |39-|48.

18. Blanchard A, Hentschel, Duffy L, Baldus K, Cassell G: Detection of Ureaplasma urealyticum by polymerase chain reaction in the urogenital tract of adult, in amniotic fluids and in the respiratory tract of newborns. Clin Infect Dis 1993, I 7(suppl): |48- I53.

19. Blanchard A, Yáñez A, Watson H, Griffiths G, Cassell G: Evaluation of intraspecies genetic variation within the rRNA gene of Mycoplasma hominis and detection by polymerase chain reaction. I Clin Microbiol I993, 3 I: | 358-I36I

20. Horowitz S, Mazor M, Horowitz J, Porath J, Glezerman M: Antibodies to Ureaplasma urealyticum in women with intraamniotic infection and adverse pregnancy outcome. Acta Obst Gynecol Scand 1995, 74:132-136.

21. Horowitz S, Horowitz J, Hou L, Fuchs E, Rager-Zisman B, Jacobs E, Alkan M: Antibodies to Mycoplasma fermentans in HIV-positive heterosexual patiens: seroprevalence and association with AIDS. J Infect 1998, 36:79-84.

22. Midtvedt $\mathrm{T}$ : Intestinal bacteria and rheumatic disease. Scand J Rheumatol 1987, 64(suppl):49-54.

23. Toivanen P: Normal intestinal microbiota in the aetiopathogenesis of rheumatoid arthritis. Ann Rheum Dis 2003, 62:807-8II.

24. Wilder RL, Crofford LJ: Do infectious agents cause rheumatoid arthritis? Clin Orthop I99I, 265:36-4I.

25. Hernández CB, Cardiel HM, Villa RM, Alcocer V]: Development, recurrence and severity of infections in Mexican patients with rheumatoid arthritis. A nested case-control-study. J Rheumatol 1998, 25:1900-1907.

26. Razin S, Yogev D, Naot EY: Molecular biology of mycoplasmas. Microbiol Mol Biol Rev 1998, 62:1094- I I56.

27. Haeir J, Nasralla M, Franco AR, Nicolson LG: Detection of mycoplasmal infections in blood of patients with rheumatoid arthritis. Rheumatol 1999, 38:504-509.

28. Cole BC, Washburn LR, Taylor-Robinson D: The mycoplasmas. In Mycoplasma pathogenicity Volume 4. Edited by: Razin S, Barile MF. New York: Academic Press; 1985:108-150.

29. Blanchard A, Gautier M, Mayau V: Detection and identification of mycoplasmas by amplification of rDNA. FEMS Microbiol Lett 1999, 8 |:37-42.

30. Hopert A, Uphoff CC, Wirt M, Hauser H, Drexter HG: Specificity and sensitivity of polymerase chain reaction (PCR) in comparison with other methods for the detection of mycoplasma contamination in cell lines. J Immunol Met 1993, 164:91-100.

31. Horowitz S, Evinson B, Horowitz J: Mycoplasma fermentans in rheumatoid arthritis and other inflammatory arthritis. J Rheumatol 2000, 27:2747-2753.

32. Hoffman RW, O'Sullivan FX, Schafermeyer KR: Mycoplasmal infection and rheumatoid arthritis: analysis of their relationship using immunoblotting and ultra sensitive polymerase chain reaction detection method. Arthritis Rheum 1997, 40:1219-1228.

33. Johnson MS, Bruckner F, Collins D: Distribution of Mycoplasma pneumoniae and Mycoplasma salivarium in the synovial fluid of arthritis patients. J Clin Microbiol 2007, 45:953-957.

34. Ramírez AS, Rosas A, Hernández-Meriain JA, Oengo JC, Saavedra P, de la FEC, Fernández A, Poveda JB: Relationship between rheumatoid arthritis and Mycoplasma pneumoniae: a case-control study. Rheumatol 2005, 44:912-914.

35. Kawahito $Y$, Ichinose S, Sano J, Tsubouchi Y, Kohno M, Yoshikawa T, Tokunaga D, Hojo T, Harasawa R, Nakano T, Matzuda K: Mycoplasma fermentans glycolipid-antigen as a pathogen of rheumatoid arthritis. Biochem Biophys Res Comm 2008, 369:56I-566.

36. Burmester GR: Hit and run or permanent hit? Is there evidence for a microbiological cause of rheumatoid arthritis? Rheumatol 1991, I 8: |443-|447.

37. Feldmann M, Brennan MB: Rheumatoid arthritis. Cell 1996, 85:307-310.

38. Katseni VL, Gilroy CB, Ryait BK, Ariyoshi K, Bieniasz PD, Weber JN, Taylor-Robinson D: Mycoplasma fermentans in individuals seropositive and seronegative for HIV-I. Lancet 1993, $341: 271-3$

39. Kingsley G, Panayi GS: Joint destruction in rheumatoid arthritis: biological bases. Clin Exp Rheumatol 1997, I 7(suppl):3-I4.
40. Ebringer A, Wilson C: HLA molecules, bacteria and autoimmunity. J Med Microbiol 2000, 49:305-3II.

4l. Ebringer A, Cunningham P, Ahmadi K, Wrigglesworth J, Hosseini R, Wilson C: Sequence similarity between HLA-DRI and DR4 subtypes associated with rheumatoid arthritis and proteus/ serratia membrane haemolysins. Ann Rheum Dis 1995, 54:216-220.

\section{Pre-publication history}

The pre-publication history for this paper can be accessed here:

http://www.biomedcentral.com/1471-2474/10/97/pre pub
Publish with Bio Med Central and every scientist can read your work free of charge

"BioMed Central will be the most significant development for disseminating the results of biomedical research in our lifetime. "

Sir Paul Nurse, Cancer Research UK

Your research papers will be:

- available free of charge to the entire biomedical community

- peer reviewed and published immediately upon acceptance

- cited in PubMed and archived on PubMed Central

- yours - you keep the copyright
BioMedcentral 